\title{
Rare brown tumour of the mandible secondary to tertiary hyperparathyroidism in a renal transplant recipient
}

\author{
Aurélien M Guéroult, ${ }^{1}$ Malcolm Cameron²
}

${ }^{1}$ Cambridge University

Hospitals NHS Foundation Trust, Cambridge, UK

${ }^{2}$ Oral and Maxillofacial

Surgery, Cambridge University Hospitals NHS Foundation Trust, Cambridge, UK

\section{Correspondence to}

Mr Malcolm Cameron,

malcolm.cameron@

addenbrookes.nhs.uk

Accepted 8 September 2019

Check for updates

(C) BMJ Publishing Group Limited 2019. No commercial re-use. See rights and permissions. Published by BMJ.

To cite: Guéroult AM, Cameron M. BMJ Case Rep 2019;12:e231231. doi:10.1136/bcr-2019231231

\section{SUMMARY}

Brown tumours are rare osteolytic lesions that occur secondary to hyperparathyroidism (HPT). In $2 \%$ of all cases, the craniofacial bones are affected, most frequently the mandible. HPT is classified according to aetiology into three types, of which tertiary HPT is the rarest. Here we present the case of a 42-year-old man who had received a renal transplant 16 years previously and was referred due to swelling on the right side of his jaw. An orthopantomogram revealed a multilocular radiolucency in the right body of the mandible. The bony lesion was treated by surgical enucleation. After histopathological examination of the lesion, the diagnosis of brown tumour of the mandible secondary to tertiary HPT was reached. The patient's recovery was uneventful and follow-up radiography showed good bone healing.

\section{BACKGROUND}

Brown tumours are rare osteolytic lesions that present in only $0.1 \%$ of all cases of hyperparathyroidism (HPT). ${ }^{1} \mathrm{HPT}$ is classified into three types: primary, secondary and tertiary. ${ }^{2}$ In the tertiary type, the parathyroid gland secretes hormone autonomously and is unresponsive to usual negative feedback signals, such as high serum calcium. This state emerges from longstanding hyperparathyroidism, usually secondary to renal failure, and persists despite return of renal function following transplantation. This report describes the rare case of a brown tumour of the mandible as the clinical presentation of tertiary HPT 16 years after renal transplant. This article adds to the small number of reported cases of this rare disease and is atypical in that a brown tumour developed despite only modest elevation of parathyroid hormone (PTH). Although rare, clinicians should consider brown tumours as a differential diagnosis for lytic bone lesions of the mandible as early diagnosis and treatment reduces the likelihood of craniofacial deformity, improving outcomes. This case highlights the role of dentists, maxillofacial surgeons and specialists in oral medicine in the multidisciplinary team for the care of renal transplant patients.

\section{CASE PRESENTATION}

A 42-year-old man was referred to the oral and maxillofacial clinic by his renal consultant with a history of right-sided swelling of the mandible.
The patient had been aware of this for the past 5 years but it had got progressively more noticeable, especially in the last $12-24$ months. He also reported subtle sensory changes around the lower half of his face on the right side. He denied any dental pain or disease. He had received a course of antibiotics from his dentist without improvement. Past medical history was notable for end stage renal disease as a result of IgA nephropathy for which he had received renal transplantation 16 years previously. He remained hypertensive. Also, the year before he had been referred to the ear, nose and throat department with a thyroid swelling. He underwent hemithyroidectomy, and the histology was consistent with a benign follicular tumour of the thyroid. There was no smoking history or any important family history.

On extraoral examination an obvious bony hard swelling arising from the right body of the mandible was present. Objectively, the patient had normal light touch sensation related to the mental branch of the trigeminal nerve although subjectively he reported subtle sensory change in this region. Intraorally, the swelling was also palpable and extended from the molar region to the lower incisors. Oral hygiene was good and his teeth looked well cared for.

\section{INVESTIGATIONS}

An orthopantomogram (OPG) revealed a multilocular lucency within the body of the mandible on the right hand side extending from the first molar (LR6) around to the left-sided lower incisors (figure 1). CT showed a $38 \times 17 \mathrm{~mm}$ expansile lesion centred on the right body of the mandible, extending to, but not crossing, the midline (figures 2,3 ). The lingual cortex appeared thinned but not breached, and the buccal cortex demonstrated a 'bubbly' expansile pattern. Erosion of the roots of the LR2-4 was visible. The right inferior alveolar nerve canal was noted to pass through the lesion, and the exiting mental nerve appeared to be displaced posteriorly. The appearance was thought to be suggestive of ameloblastoma and atypical of a brown tumour.

Serum biochemistry showed elevated PTH (20 pmol/L, normal range $1.48-7.63 \mathrm{pmol} / \mathrm{L})$, upper range of normal calcium $(2.58 \mathrm{mmol} / \mathrm{L}$, normal range $2.08-2.65 \mathrm{mmol} / \mathrm{L}$ ) and normal range of alkaline phosphatase and phosphate. Estimated glomerular filtration rate was $62 \mathrm{~mL} / \mathrm{min} / 1.73 \mathrm{~m}^{2}$ 


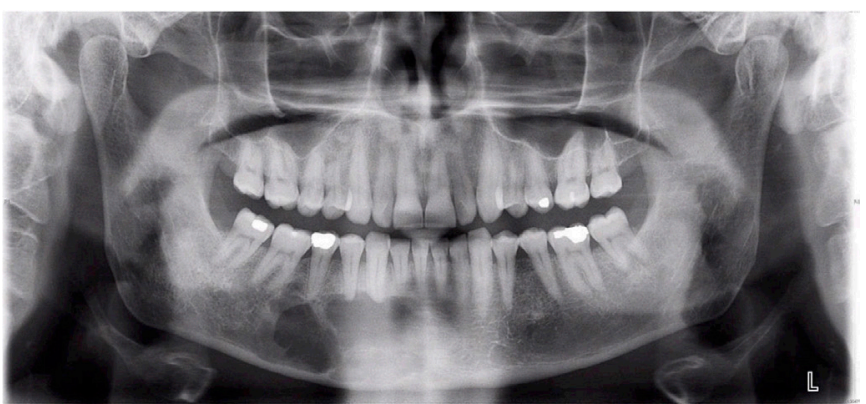

Figure 1 An orthopantomogram (OPG) showing a multilocular lucency within the body of the mandible on the right hand side.

and creatinine was $123 \mu \mathrm{mol} / \mathrm{l}$. Neck ultrasound a year previously showed no signs of enlarged parathyroid glands.

Enucleation of the lesion was performed. Macroscopically, it was firm, friable and pale brown with darker spots which might have been compatible with haemosiderin deposits. Histopathological examination revealed that the sample comprised numerous pieces of bone within which neoplastic growth was found. These were composed of bland spindle cells growing haphazardly with numerous scattered multinucleated giant cells. The tumour appeared to merge with the surrounding bone which displayed remodelling changes, including osteoid formation at the border with the neoplastic growth. There was no evidence of malignancy. In the clinical context of hyperparathyroidism, these histopathological features were consistent with brown tumour of the mandible. This was the final diagnosis .

\section{DIFFERENTIAL DIAGNOSIS}

The radiological appearance of the lesion was in keeping with an ameloblastoma although these typically arise in the ramus and body of the mandible and are only occasionally seen at the symphysis. Other diagnoses included a central giant cell granuloma (CGCG) and glandular odontogenic cyst although the latter lesion is very rare. The lesion was not typical of common odontogenic cysts, such as apical or periodontal cysts, because of its extent, multilocular appearance and erosion of the apices

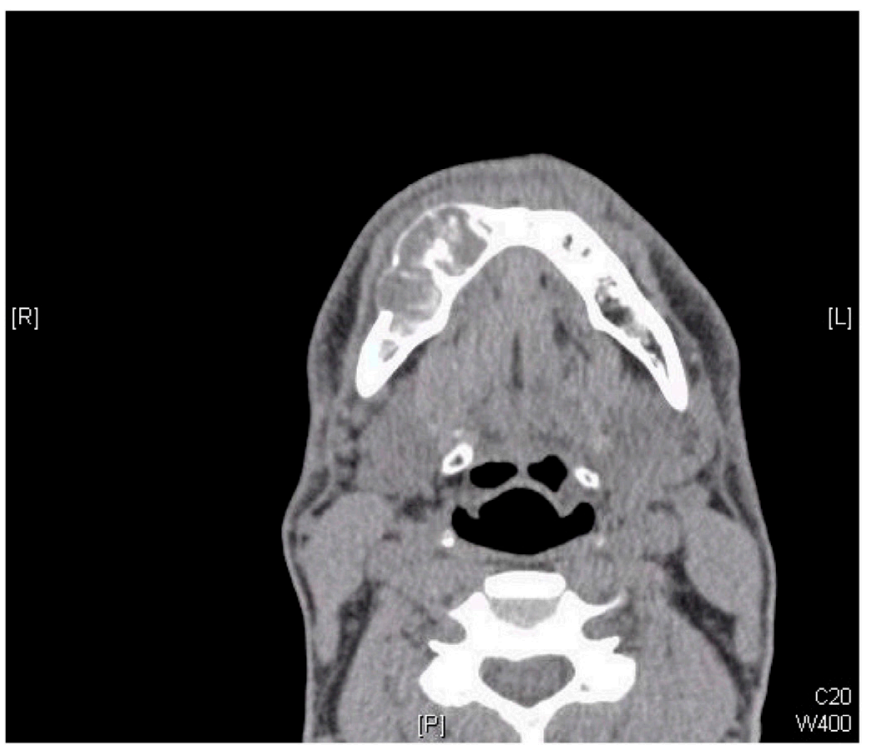

Figure 2 CT image of the mandible without contrast showing an expansile lesion centred on the right body of the mandible and thinning of the cortical bone.

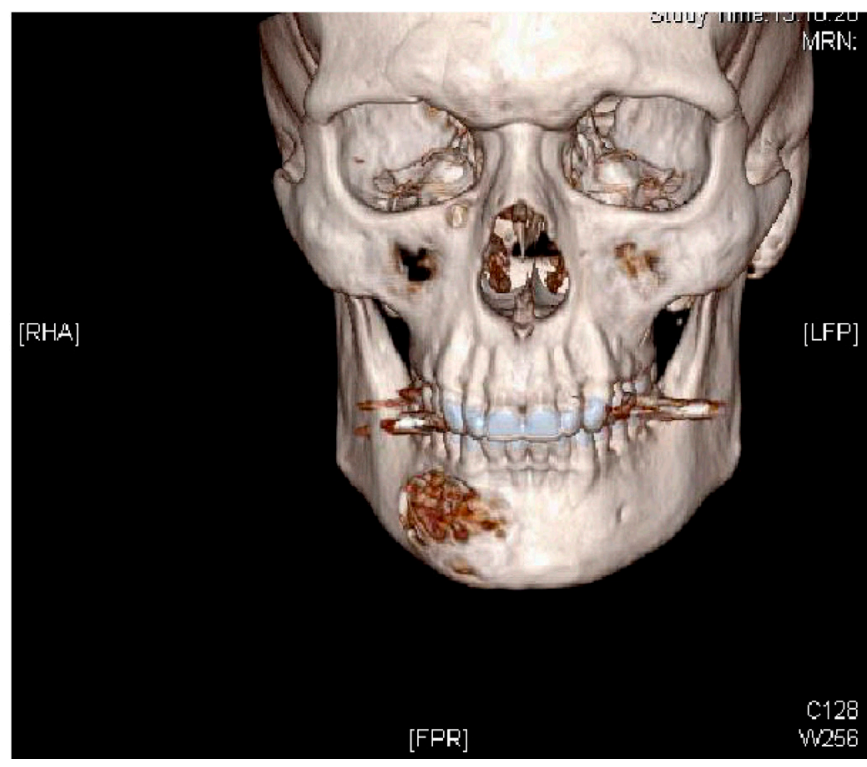

Figure 3 Three-dimensional CT image of the lesion.

of several teeth. Ameloblastoma was favoured over other differentials, such as CGCG, because of the patient's age. Typically, ameloblastomata occur in the third to fifth decades of life, while CGCGs manifest earlier in life $(75 \%$ of patients are $<30$ years of age). ${ }^{3}$ The related diagnosis of a brown tumour, which is essentially a central giant cell lesion, was evoked at this stage but it was thought less probable because of only a modest elevation in PTH. From the histopathological findings, CGCG was again considered, but in the clinical context of tertiary hyperparathyroidism brown tumour was favoured as the definitive diagnosis. A lingual salivary gland inclusion defect was also considered, although briefly, as radiological findings were not consistent with the pathognomonic features for this diagnosis. ${ }^{3}$

\section{TREATMENT}

A vestibular sulcular incision was made from LR8 to LL2, with relieving incisions on both sides. Creation of a bone window in the symphysis area exposed a firm underlying tumour, with dark brown spots. The tumour was then enucleated and came out in multiple friable fragments, some of which had the appearance of immature bone. The inferior alveolar nerve was dissected from the surrounding tumour and preserved.

\section{OUTCOME AND FOLLOW-UP}

The patient made an uneventful recovery. In light of the histopathological analysis of the tumour, his dose of alfacalcidol was increased to $500 \mathrm{ng}$ three times a week (he had previously been taking $250 \mathrm{ng}$ three times a week). The patient was reviewed in clinic at 3 weeks and 6 months postoperatively. At his first review, he reported a little sensory change of the lip, chin and lower teeth on the right side; this had been anticipated and discussed at his preoperative clinic visit. At 6 months, his sensation was completely recovered, the surgical site had healed well and there was no evidence of swelling in the area. An OPG at this time demonstrated good infill of the bone defect on the right hand side (figure 4). At 5 months postoperatively, PTH was $19.5 \mathrm{pmol} / \mathrm{L}$ and vitamin $\mathrm{D}$ was $37.8 \mathrm{nmol} / \mathrm{L}$. The patient is currently followed-up every 4 months by a nephrologist and every 6 months by a maxillofacial surgeon. 


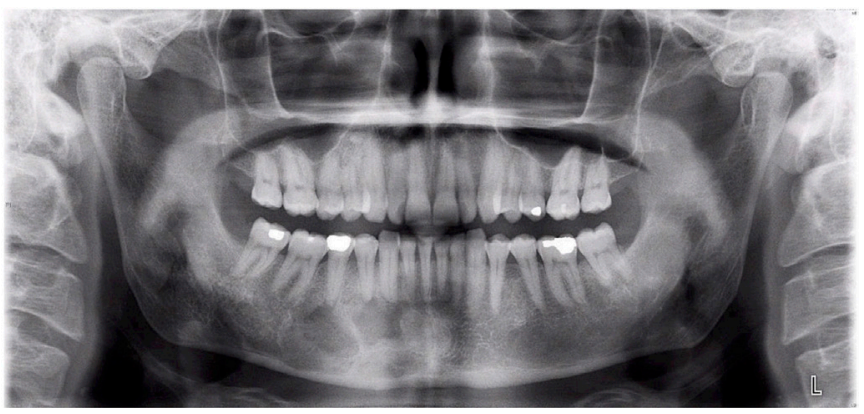

Figure 4 Follow-up orthopantomogram (OPG) after 6 months showing good infill of the bone defect on the right side.

\section{DISCUSSION}

HPT is classified according to the cause of the underlying hypersecretion into primary, secondary and tertiary types. ${ }^{2}$ Primary HPT is a consequence of intrinsic pathology of the gland, such as parathyroid hyperplasia (10-15\%), adenoma (80-90\%) or carcinoma (1\%). ${ }^{1}$ Secondary HPT is a compensatory response to hypocalcaemia, often caused by chronic kidney disease. The poorly functioning kidneys are unable to catalyse the final hydroxylation step in the metabolism of vitamin D, and so the circulating levels of bioactive vitamin D3 are inadequate. As a result, intestinal absorption and renal tubular reabsorption of calcium are reduced, leading to hypocalcaemia. Dietary insufficiency of vitamin D is also a reported cause of secondary HPT. Tertiary HPT develops from a period of chronic secondary HPT.

Here, the parathyroid glands continued to oversecrete PTH independently of previous causative disease and normal negative feedback signals (such as high/normal serum calcium). It is seen in renal transplant recipients who have had chronic secondary HPT, and despite restoration of renal function post-transplant, they continue to be hyperparathyroid. Tertiary HPT is uncommon, affecting only $8 \%$ of renal transplant recipients with a history of secondary HPT. ${ }^{4}$

Brown tumours are a rare consequence of longstanding HPT; they are seen in $4 \%$ of primary HPT cases and in $1.5 \%$ of secondary HPT cases. ${ }^{5}$ They are the end point of bone remodelling activity stimulated by HPT and involve the ribs, clavicles, pelvis, femur, vertebrae and craniofacial bones (the mandible is more commonly affected than the maxilla). On histopathological examination, multi-nucleated giant cells are visualised scattered among stromal cells and matrix. The name 'brown tumour' refers to the tissue's colour caused by haemorrhagic degeneration of demineralised stroma and subsequent haemosiderin deposition. ${ }^{6}$ There are no histological findings that are pathognomonic for brown tumours. Indeed, reparative granulomata and giant cell tumours of bone will have indistinguishable histological appearances. Thus brown tumours are only differentiated by a clinical context of HPT.

Of the five reported cases of craniofacial brown tumours of tertiary hyperparathyroidism, ${ }^{4-10}$ only one records occurrence in a renal transplant recipient. ${ }^{4}$ Compared with the case reported here, PTH was much higher $(116 \mathrm{pmol} / \mathrm{L}$, compared with $20 \mathrm{pmol} / \mathrm{L}$ in our patient) and the tumour was symptomatic much sooner post-transplantation (6 years after first transplant, compared with 16 years in our case). In a review of craniofacial brown tumours, a correlation between serum PTH and brown tumour occurrence was identified. ${ }^{11}$ In each of the five cases, PTH level was in excess of $107 \mathrm{pmol} / \mathrm{L}$ (normal range $1.48-7.63 \mathrm{pmol} / \mathrm{L}$ ). Our case suggests that chronic HPT, despite only modest elevation, may also cause brown tumours many

\section{Patient's perspective}

Right from the first consultation I was made to feel reassured that I would be well looked after. I had a very positive experience both pre and post operation and the recovery went very well. Hopefully the ongoing investigation into the cause of the growth will provide a better understanding to its cause and future treatments.

\section{Learning points}

- Brown tumours may develop despite only modest hyperparathyroidism.

- Radiological appearance of a brown tumour may mimic central giant cell granuloma, lingual salivary gland inclusion defect and ameloblastoma.

- Surgical excision gives good outcomes and is indicated if the brown tumour causes pain or deformity.

- Although rare, clinicians should consider brown tumours as a differential diagnosis for lytic bone lesions of the mandible as early diagnosis and treatment reduces the likelihood of craniofacial deformity, improving outcomes.

- Dentists and maxillofacial surgeons have a role to play in the multidisciplinary team for renal transplant patients.

years post-transplantation. Furthermore, this report suggests that surgical excision has a good outcome and is indicated if the tumour causes pain or facial deformity.

This case highlights the fact that dental practitioners have the potential to play an important part in the multidisciplinary team for the care of renal transplant recipients. ${ }^{12}$ Dentists provide regular surveillance of the oral cavity, which is important for immunosuppressed patients to facilitate treatment of common problems, such as oral infections and xerostomia. ${ }^{12-14}$ Although rare, dentists should be aware of brown tumours of HPT as early detection and treatment reduces the likelihood of bone fracture and craniofacial deformity, improving outcomes.

Contributors The case report was mostly written by AMG; MC read and edited the original report and is the supervising consultant.

Funding The authors have not declared a specific grant for this research from any funding agency in the public, commercial or not-for-profit sectors. With

Competing interests None declared.

Patient consent for publication Obtained

Provenance and peer review Not commissioned; externally peer reviewed.

\section{REFERENCES}

1 Talukder S, Behera A, Bhadada SK, et al. Giant mediastinal parathyroid adenoma presenting as bilateral brown tumour of mandible: a rare presentation of primary hyperparathyroidism. BMJ Case Rep 2017;2017:bcr-2017-220722.

2 Palla B, Burian E, Fliefel $R$, et al. Systematic review of oral manifestations related to hyperparathyroidism. Clin Oral Investig 2018;22:1-27.

3 Scholl RJ, Kellett HM, Neumann DP, et al. Cysts and cystic lesions of the mandible: clinical and radiologic-histopathologic review. Radiographics 1999;19:1107-24.

4 Magalhães DP, Osterne RL, Alves AP, et al. Multiple brown tumours of tertiary hyperparathyroidism in a renal transplant recipient: a case report. Med Oral Patol Oral Cir Bucal 2010;15:e10-13.

5 Lessa MM, Sakae FA, Tsuji RK, et al. Brown tumor of the facial bones: case report and literature review. Ear Nose Throat J 2005;84:432-4.

6 Nair PP, Gharote HP, Thomas S, et al. Brown tumour of the jaw. BMJ Case Rep 2011:4-7.

7 Macdonald DS, Zhang L, Gu Y. Calcification of the external carotid arteries and their branches. Dentomaxillofac Radiol 2012;41:615-8. 
8 Selvi F, Cakarer S, Tanakol R, et al. Brown tumour of the maxilla and mandible: a rare complication of tertiary hyperparathyroidism. Dentomaxillofac Radiol 2009;38:53-8.

9 Dorigatti de Ávila É, de Molon RS, Cabrini Gabrielli MA, et al. Unusually rapid growth of brown tumour in the mandible after parathyroidectomy associated with the presence of a supernumerary parathyroid gland. J Craniomaxillofac Surg 2012:40:e19-23.

10 Pinto LP, Cherubinim K, Salum FG, et al. Highly aggressive brown tumor in the jaw associated with tertiary hyperparathyroidism. Pediatr Dent 2006;28:543-6.
11 Cecchetti DF, Paula SA, Cruz AA, et al. Orbital involvement in craniofacial brown tumors. Ophthalmic Plast Reconstr Surg 2010;26:106-11.

12 Kamala K, Gupta P. Oral consideration and dental management in organ transplant patient. J Int Oral Health 2010:2:1-8.

13 Levarda-Hudolin K, Hudolin T, Bašić-Jukić N, et al. Oral lesions in kidney transplant recipients. Acta Clin Croat 2016:55:459-63.

14 Dirschnabel AJ, Martins AS, Dantas SA, et al. Clinical oral findings in dialysis and kidney-transplant patients. Quintessence Int 2011:42:127-33.

Copyright 2019 BMJ Publishing Group. All rights reserved. For permission to reuse any of this content visit https://www.bmj.com/company/products-services/rights-and-licensing/permissions/

BMJ Case Report Fellows may re-use this article for personal use and teaching without any further permission.

Become a Fellow of BMJ Case Reports today and you can:

- Submit as many cases as you like

- Enjoy fast sympathetic peer review and rapid publication of accepted articles

Access all the published articles

Re-use any of the published material for personal use and teaching without further permission

\section{Customer Service}

If you have any further queries about your subscription, please contact our customer services team on +44 (0) 2071111105 or via email at support@bmj.com.

Visit casereports.bmj.com for more articles like this and to become a Fellow 